\title{
Topology Optimization of Rotor Structure in Permanent Magnet Synchronous Motors Considering Ease of Manufacturing
}

\author{
Takeo Ishikawa*a) $^{*}$ Senior Member, Peijie Xie ${ }^{*}$ Student Member \\ Nobuyuki Kurita* Member
}

(Manuscript received Feb. 19, 2014, revised Nov. 20, 2014)

\begin{abstract}
This paper designs the rotor structure for two types of permanent magnet synchronous motors. The proposed optimization method combines a topology optimization method, which uses a genetic algorithm and a cleaning procedure, and a method considering ease of manufacturing. The designed rotor of a compressor motor for an air conditioner has $32 \%$ higher average torque than that of a conventional motor. The designed rotor has a larger torque/current than that of a hybrid vehicle motor at a low output power.
\end{abstract}

Keywords: topology optimization, genetic algorithm, permanent magnet synchronous motor, finite element method, manufacturing

\section{Introduction}

Many methodologies for permanent magnet (PM) rotor topology have been developed for high output power; e.g., surface permanent magnets (SPMs), interior permanent magnets (IPMs), and flux-barriers. In particular, the geometry of the IPM rotor has been investigated for several reasons, including the reduction of cogging torque by adjusting the pole ratio, PM asymmetry arrangement, and adopting semiclosed and auxiliary slots in the stator core to improve the performance of sensorless drives ${ }^{(1)-(3)}$. Further, the geometry of the IPM rotor has been studied to reduce harmonic iron losses ${ }^{(4)-(6)}$. The rotor geometry of a PM motor significantly affects motor performance; therefore, it is important to develop an initial conceptual structural topology of an IPM rotor.

Several types of promising topology optimization procedures have been proposed. Topology optimization allows obtaining an initial conceptual structure starting with minimal information regarding the structure of the object. Topology optimization methods were proposed about twenty years ago $^{(7)(8)}$. Since then, several papers have been published in this field. For example, Byun et al. proposed topology optimization with design sensitivity ${ }^{(9)}$. Im et al. proposed the local optimization algorithm, called the ON/OFF sensitivity method, hybridized with a genetic algorithm (GA) to improve convergence characteristics ${ }^{(10)}$. Wang et al. designed electromagnetic systems by topology optimization considering magnetization direction ${ }^{(11)}$. Shim et al. proposed topology optimization coupled with magneto-thermal systems ${ }^{(12)}$. Kim et al. designed a 3D electromagnetic device with soft magnetic composites using the topology optimization method ${ }^{(13)}$. Choi et al. proposed an optimization method

a) Correspondence to: Takeo Ishikawa. E-mail: ishi@el.gunmau.ac.jp

* Division of Electronics and Informatics, Gunma University

1-5-1, Tenjin-cho, Kiryu, Gunma 376-8515, Japan using the genetic algorithm and ON/OFF sensitivity in conjunction with the blurring technique to avoid small structure spots ${ }^{(14)}$. Labbe et al. considered the mapping function to improve convexity in the topology optimization procedure $^{(15)}$. Kikuchi et al. applied topology optimization to the coupled magnetic structural problem ${ }^{(16)}$. Takahashi et al. designed an IPM motor using the ON/OFF method by considering magnetic nonlinearity and rotation ${ }^{(17)}$. Park et al. optimized magnetic actuators using a level-set method ${ }^{(18)}$. Watanabe et al. optimized an inductor using the evolutionary algorithm ${ }^{(19)}$. Okamoto et al. proposed a 3D topological optimization method based on the multistep utilization of GA ${ }^{(20)}$. Hahn presented a possible solution to the structural optimization problem using a simple heuristic search algorithm ${ }^{(21)}$.

We proposed a topology optimization method to optimize the distribution of materials within an electrical machine using the $\mathrm{GA}^{(22)}$. In addition, we proposed a concept for the cluster of materials and a cleaning procedure for the materials, and we designed the stator of a brushless DC motor based on this method ${ }^{(23)}$. However, that study considered only two types of materials, air and iron, and therefore, it is similar to the ON/OFF method. We improved the previous method in order to consider more than two materials-namely, air and iron as well as $r$-oriented, $x$-oriented, and $y$-oriented magnets ${ }^{(24)}$. Moreover, initially, the obtained rotor structure was assumed to consist of the simple shape of PMs in order to consider ease of manufacturing ${ }^{(25)}$.

This paper applies the proposed topology optimization method to the design of the rotor structure for two types of PM synchronous motors. One is an interior permanent magnet synchronous motor (IPMSM) used for air conditioning, and the other is similar to an IPMSM used in a Toyota Prius. The average torque characteristics of IPMSMs are compared with these motors. 


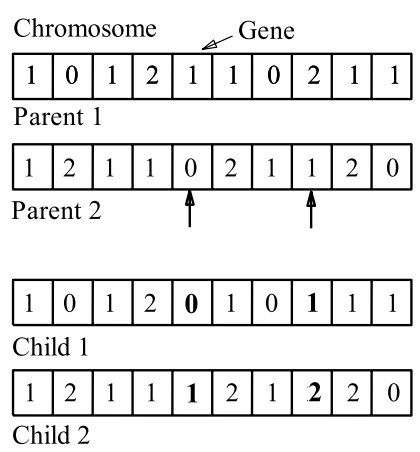

Fig. 1. Example of genes and uniform crossover in GA

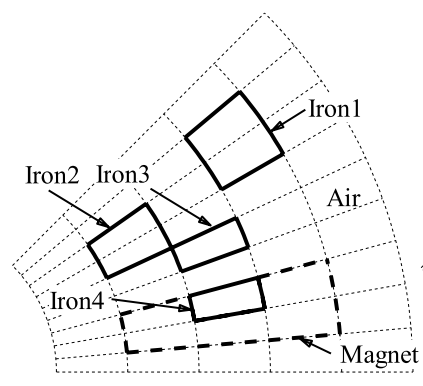

(a) Before cleaning

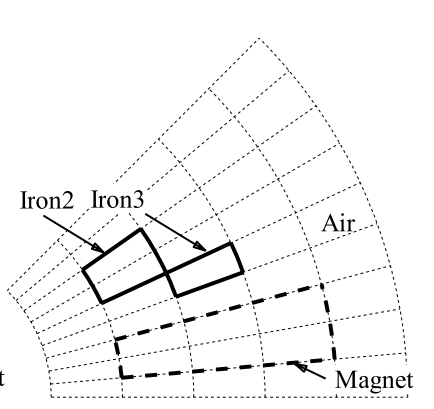

(b) After cleaning
Fig. 2. Cluster of materials and the cleaning method concept

\section{Design using the Topology Optimization Method}

\subsection{Implemented Topology Optimization Method}

In this section, we briefly explain the topology optimization method proposed in (24), which is implemented in this study. GA is an algorithm that imitates the evolution of living things and is suitable for problems with a large sample space. In the proposed method, the design region is split into finite element meshes, and the materials of several elements-e.g., a cellis associated with a gene in the chromosome. For example, if we consider three types of materials-e.g., air, iron, and magnet, which are set to 0,1 , and 2 , respectively-the chromosome is composed of some genes as shown in Fig. 1. Two parents are selected randomly and some genes are selected to be exchanged by a uniform crossover with a crossover ratio, and then, two new children are generated as shown in Fig. 1. The children inherit the good characteristics of parents by repeating the process. We proposed the concept of the cluster with many types of materials. For example, irons 2 and 3 form the same cluster, and iron 1 forms another cluster, as shown in Fig. 2(a). If the cluster is small-that is, the number of cells in the region is smaller than or equal to an integer $N_{\min }$ - the cleaning procedure is carried out. Then, irons 2 and 3 remain, and the other irons are dismissed. Iron 1 is changed to the surrounding material, air, and iron 4 is changed to the magnet as shown in Fig. 2(b). This cleaning procedure for a small cluster of materials can remove the floating pieces of the material.

Figure 3 shows the cross section of a four-pole PM synchronous motor with distributed windings. One-eighth of the rotor is designed for symmetry. This paper iterates the GA with the newly increased length of genes. For the first iteration, a coarse topology is designed using a small number of

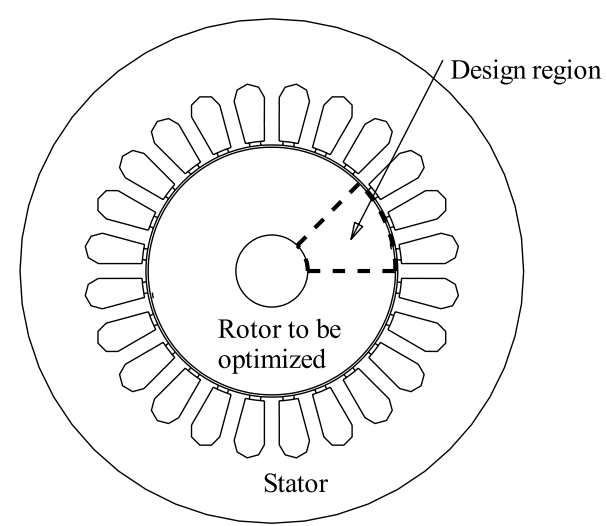

Fig. 3. Motor cross section and design region

Table 1. Parameters for design

\begin{tabular}{|c|c|c|c|}
\hline Figure & Material & $\begin{array}{c}N_{\min } \text { at } 1^{\text {st }} \\
\text { iteration }\end{array}$ & $\begin{array}{c}N_{\min } \text { at } 2^{\text {nd }} \\
\text { iteration }\end{array}$ \\
\hline Fig. 5 & $\begin{array}{c}\text { Air, iron, } \\
r \text {-oriented PM }\end{array}$ & 1 & 4 \\
\hline Fig. 6(a) & $\begin{array}{c}\text { Air, iron, } x \text {-, } \\
y \text {-oriented PM }\end{array}$ & 1 & 4 \\
\hline Fig. 6(b) & $\begin{array}{c}\text { Air, iron, } x \text {-, } \\
y \text {-oriented PM }\end{array}$ & $\begin{array}{c}1 \text { for air and } \\
\text { iron, 0 for PM }\end{array}$ & 4 \\
\hline Fig. 7 & $\begin{array}{c}\text { Air, iron, } \\
r \text {-oriented PM }\end{array}$ & 0 & 0 \\
\hline
\end{tabular}

design variables in a $5 \times 9$ array of cells. A fine topology then is designed using a large number of design variables for the second iteration in a $20 \times 18$ array of cells. For the second iteration, a set of initial individuals in the GA inherit the individual that has the best fitness at the conclusion of the previous iteration. The parameter $N_{\text {min }}$ of the cleaning procedure at each iteration is listed in Table 1.

In order to acquire the structure for high average torque and restrain the volume of the $\mathrm{PM}$, the fitness function is defined as

$$
\text { fitness }=\frac{T_{\text {ave }}}{V_{p m} / V_{\text {rotor }}+1} .
$$

where, $T_{\text {ave }}, V_{p m}$, and $V_{\text {rotor }}$ are the average torque, the volume of the PM, and the volume of the rotor, respectively. $V_{\text {rotor }}$ is constant in this paper because only the arrangement of the PM and air (flux-barrier) is optimized without a change in rotor diameter and stack length. Hence, the fitness function is directly proportional to $T_{\text {ave }}$ and inversely proportional to $V_{p m}$.

2.2 Rotor Structure Obtained by the Topology Optimization Method This paper optimizes the topology of the rotor structure by considering two types of PMs-roriented magnet only, and both $x$ - and $y$-oriented magnets. We set the number of populations to be 45 . If a number larger than 45 is selected, there is a possibility for a better result. However, this would lead to a longer computational time. Figure 4 shows a convergence characteristic of the applied topology optimization. We find that the fitness functions almost converge at every iteration-namely, at every 300th generation.

Figure 5 shows the obtained rotor structures, in which three types of materials — air, iron, and the $r$-oriented magnet —are 


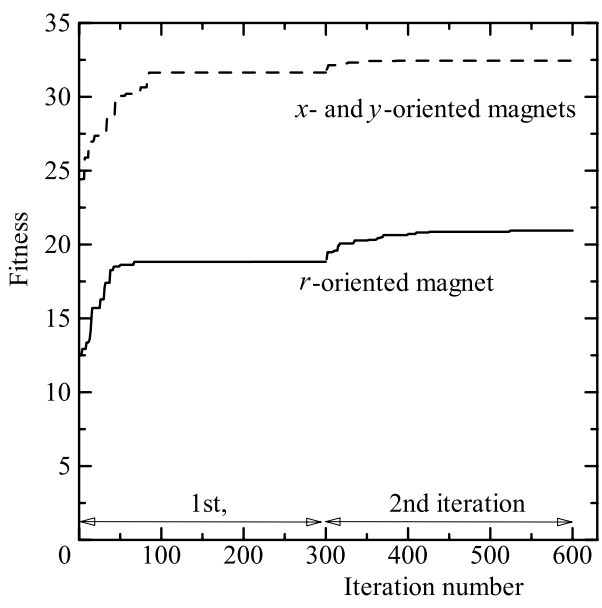

Fig. 4. Convergence characteristic of the topology optimization

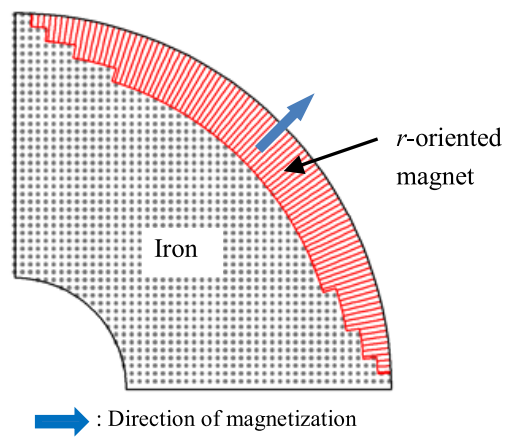

Fig. 5. Rotor structure obtained by considering air, iron, and the $r$-oriented PM

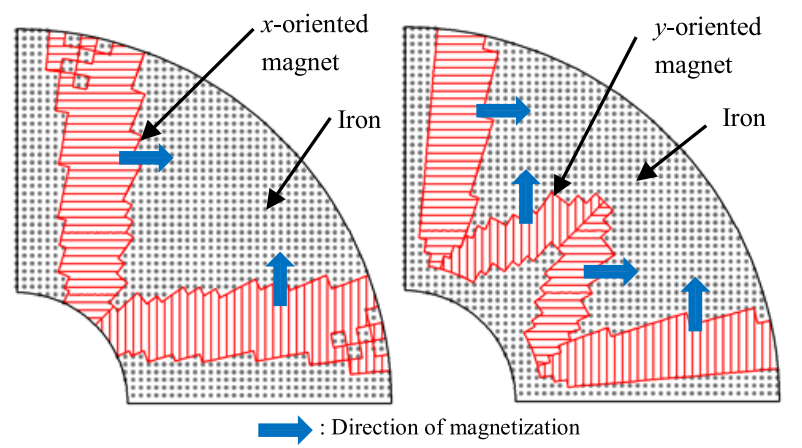

(a)

(b)

Fig. 6. Rotor structures obtained by considering air, iron, $x$ - and $y$ - oriented PMs, (a) with and (b) without the cleaning procedure for PMs at the first iteration

considered. $N_{\min }$ is set to be 1 for air and iron at the first iteration. This means that if the number of cells is equal to 1 , the material of the cell is changed to the surrounding material. $N_{\min }$ is set to 4 at the second iteration. Design parameters are shown in Table 1 . The optimization by considering the $r$-oriented magnet only produces a kind of surface PM-type rotor.

Figure 6 shows the obtained rotor structure by considering $x$ - and $y$-oriented magnets produces a kind of interior PMtype rotor. The parameters listed in Table 1 are used for the cleaning procedure. The rotor shapes appears as $\mathrm{V}$ and $\mathrm{W}$. The V shape was obtained when the cleaning procedure was carried out for the PM material at the first iteration, and the

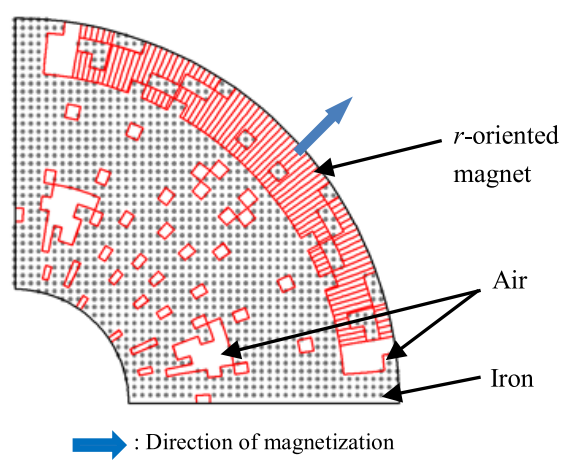

Fig. 7. Rotor structure obtained by considering air, iron, and $r$-oriented PM without considering the cleaning procedure for each material

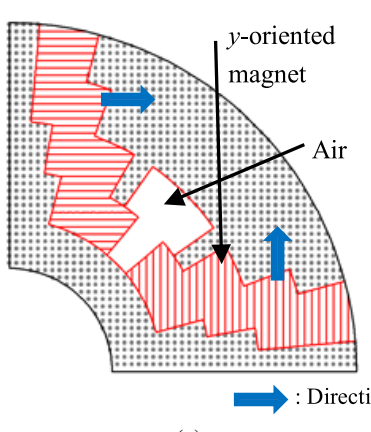

(a)

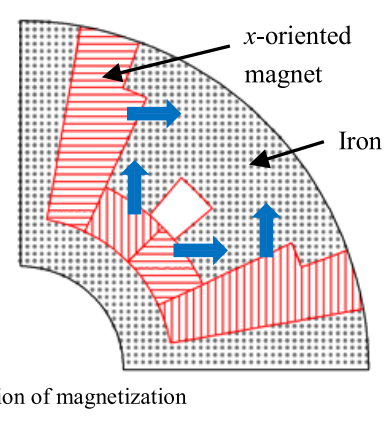

(b)
Fig. 8. Rotor structures obtained at the first iteration by considering air, iron, $x$ - and $y$ - oriented PMs, (a) with and (b) without the cleaning procedure for the PM

W shape was obtained when the cleaning procedure was not carried out for the PM material at the first iteration.

2.3 Discussion on Obtained Rotor Structures Figure 7 shows the obtained rotor structure when the cluster of material and the cleaning method are not carried out. $T_{\text {ave }}$ and $V_{p m}$ for Fig. 7 are $5.38 \mathrm{~N} \cdot \mathrm{m}$ and $23.2 \mathrm{~cm}^{3}$, respectively, and for Fig. 5, they are $6.16 \mathrm{~N} \cdot \mathrm{m}$ and $31.6 \mathrm{~cm}^{3}$, respectively. Although the obtained magnet shape appears similar to that shown in Fig. 5, the rotor has numerous small pieces of iron in the $r$-oriented magnet. As mentioned in Sect. 2.1, the cleaning procedure can remove the small cluster of materials. Therefore, the structure obtained without considering the cleaning procedure has numerous small pieces of iron in the magnet and numerous pockets of air in the iron, which are shown in Fig. 7. This rotor has a complicated, weak structure and is difficult to manufacture.

The optimized rotor shapes shown in Fig. 6 appear as V and W. Let us discuss what causes this difference. Figure 8 shows the obtained shapes at the first iteration with and without considering the cleaning procedure for the PM materials. When the cleaning procedure is not carried out for PM materials, small PM cells can easily remain in the GA procedure. As a result, Fig. 8(a) does not include the $x$-oriented magnet at the center, whereas Fig. 8(b) includes the $x$-oriented magnet at the center. The $x$-oriented magnet shown in Fig. 8(b) remains in the next iteration, and the final shape, which includes the $x$-oriented magnet, is then obtained as shown in Fig. 6(b). 


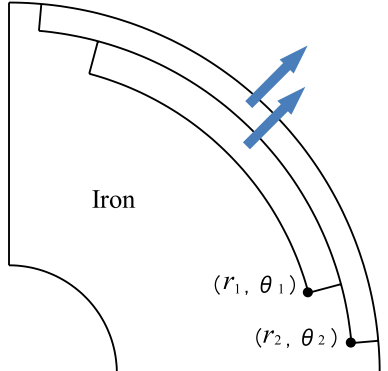

(a) For Fig. 5

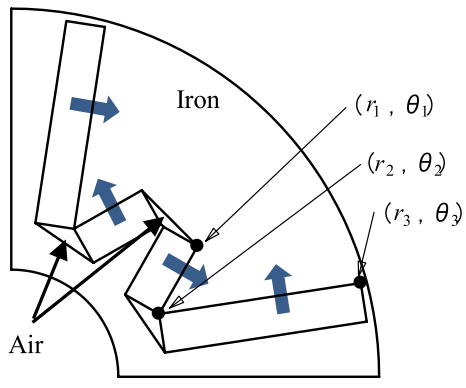

(b) For Fig. 6

Fig. 9. Rotor structures represented by simple magnet shape

\section{Optimization Considering Ease of Manufac- turing}

3.1 Possible Practical Realization The obtained rotor structures are complex and impractical. In order to consider the ease of manufacturing, magnets and air pockets are assumed to be simple shapes, and they are then optimized using conventional techniques. For example, the rotor structures shown in Fig. 5 can be assumed to be similar to the ones in Fig. 9(a), where the magnets are represented by four parameters. The rotor structure shown in Fig. 6 can be assumed to contain four hexahedron PMs as shown in Fig. 9(b). In this shape, the rotor structure is represented by six parameters if the thickness of the magnets is uniform and the volume of the magnets is specified. This paper assumes that the shape of each magnet is a hexahedron and the magnet is magnetized in the vertical direction as shown in Fig. 9(b) for the ease of magnetization. Moreover, this paper assumes that a core area is introduced on the surface of the rotor as shown in Fig. 9(b) to insure machine strength against centrifugal force. Therefore, parameter $r_{3}$ is fixed, and then, the number of design parameters is five.

3.2 Designed Rotor Structure of a Compressor Motor

The first example is the rotor of an experimental motor. This experimental motor is well known as D model in IEE Japan for an air conditioner and has an IPM-type rotor. This paper uses a full search method to optimize the rotor shape, because we want to verify that there is a good rotor shape similar to those shown in Fig. 6. The angle of position A is set to five values, and the radius and angle of position $\mathrm{B}$ and $\mathrm{C}$, respectively, are also set to five values. This gives $5^{5}=3,125$ patterns to be calculated in the full search method. This paper iterates the full search method twice, where the variation of each parameter is set to approximately half, and the phase angle of stator current is set to $15,20,25$, and $30^{\circ}$. The finite element mesh is generated automatically using the Delaunay

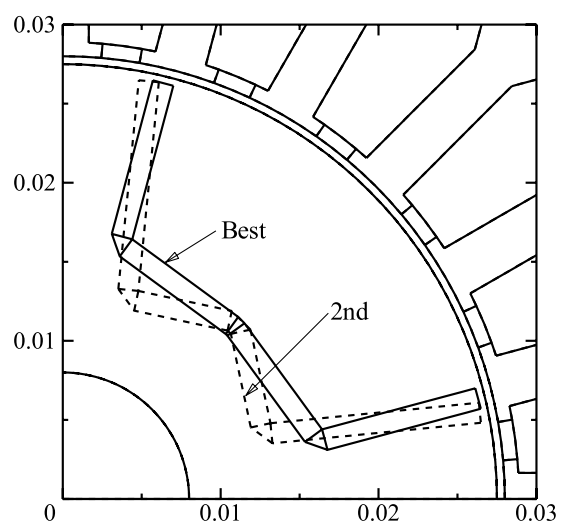

Fig. 10. Obtained rotor structure of an air conditioner

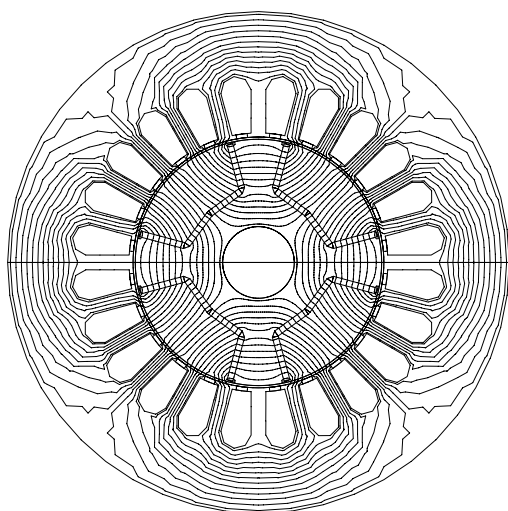

(a) Designed motor.

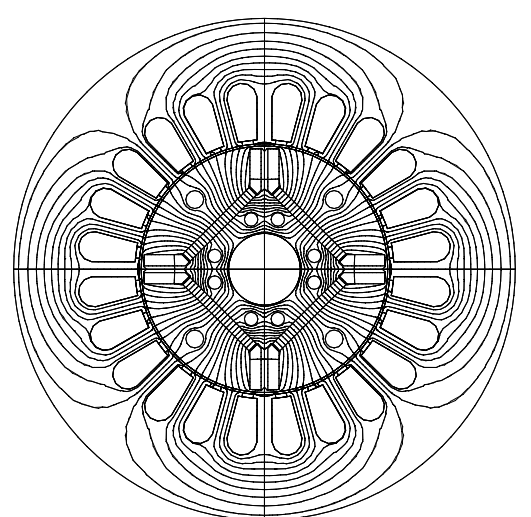

(b) Experimental motor.

Fig. 11. Obtained rotor structure and flux distribution at no load

method, and the torque is calculated using Maxwell's tensor method in the full search method.

Figure 10 shows the obtained rotor structure, where the "best" rotor structure provides the largest average torque at the second iteration of the full search method, and the " 2 nd" one provides the second-largest average torque at the first iteration. It was found that the "best" rotor structure is Ushaped and the "2nd" is W-shaped. Figure 11(a) shows the obtained rotor structure and its flux distribution at no load. Figure 11(b) shows the flux distribution of an experimental motor whose stator is the same as that shown in Fig. 11(a). The ratings of the experimental motor are $1.5 \mathrm{~kW}$, $3,000 \mathrm{~min}^{-1}, 192 \mathrm{~V}$, and $5.6 \mathrm{~A}$; the main dimensions are a stator diameter of $112 \mathrm{~mm}$, a rotor diameter of $55 \mathrm{~mm}$, and an air gap length of $0.5 \mathrm{~mm}$. It is found that the flux linkage 


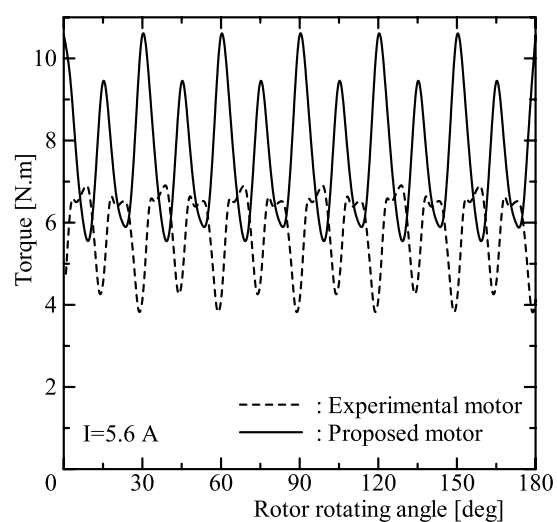

Fig. 12. Comparison of torque with an experimental motor

is increased by approximately $50 \%$ because of the long, thin magnets of the optimized rotor. Figure 12 shows the comparison of the developed torque with the experimental motor. The average torque is increased from $5.8 \mathrm{~N} \cdot \mathrm{m}$ to $7 \cdot 6 \mathrm{~N} \cdot \mathrm{m}$ - that is, by approximately $32 \%$ - because of the increase of magnetic flux produced by the PMs. However, the torque ripple of the proposed motor is increased because it is not considered by the fitness function.

The calculated torque of the "2nd" rotor structure is almost the same as that of the "best" rotor structure. This means that the shape of the PM in the inside rotor is not a significant factor in the torque provided. Therefore, we believe that two types of rotor structure have been obtained by the proposed method as shown in Fig. 6.

3.3 Designed Rotor Structure for a Hybrid Vehicle Motor The next example is the rotor of a motor similar to that of the Toyota Prius. The word similar is used to mean that the dimensions are approximately the same. This paper assumes that iron is made of 50A400 and the residual flux density of the PM is $1.26 \mathrm{~T}$. The same optimization process as that shown in Fig. 11(a) is applied. Because this motor has eight poles, the number of slots per pole is the same as the first example shown in Fig. 11. Consequently, this paper assumes that the rotor structure designed by the proposed GA-considering the cluster of materials and the cleaning procedure-becomes $\mathrm{V}$ - or $\mathrm{W}$ - shaped. The rotor structure of one-fourth in Fig. 9(b) is changed to one-eighth and is designed by the full search method. Figure 13(a) shows the obtained rotor structure and its flux distribution at no load, and Fig. 13(b) shows the flux distribution of the Prius-like motor. It is found that the flux linkage is increased by approximately $34 \%$ because of the long, thin magnets of the optimized rotor. Figures 14 and 15 show the comparison of the developed torque with the experimental motor. Unfortunately, the average torque decreases from $455 \mathrm{~N} \cdot \mathrm{m}$ to $431 \mathrm{~N} \cdot \mathrm{m}$ - that is, by approximately $5 \%$ - at the rated stator current of $176.75 \mathrm{~A}$. However, it increases when the stator current is less than $125 \mathrm{~A}$; e.g., from $257 \mathrm{~N} \cdot \mathrm{m}$ to $267 \mathrm{~N} \cdot \mathrm{m}$ - that is, by approximately $4 \%$-at the stator current of $100 \mathrm{~A}$. Figure 15 indicates that the designed motor has a larger torque/current than that of the Prius-like motor at a low output power. Further, the torque ripple decreases at the rated stator current.

In this section, we discuss the reduction of the average torque at the rated current. Figure 16 shows the $d$ - and

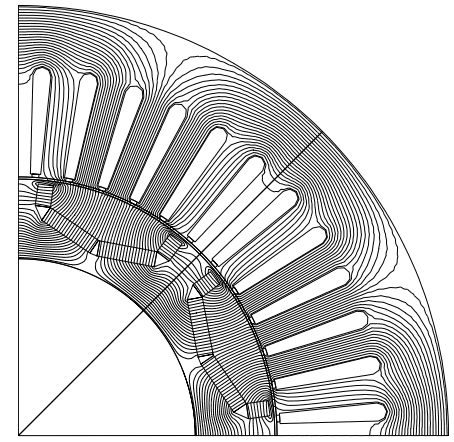

(a) Designed motor.

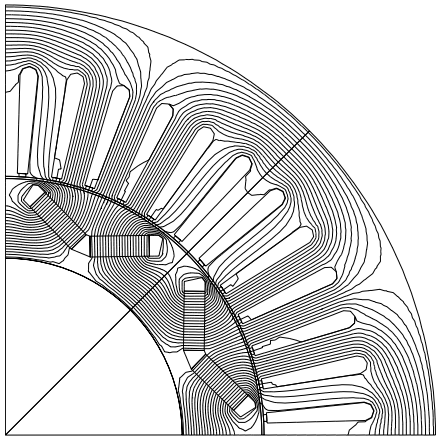

(b) Prius-like motor.

Fig. 13. Obtained rotor structure and flux distribution at no load

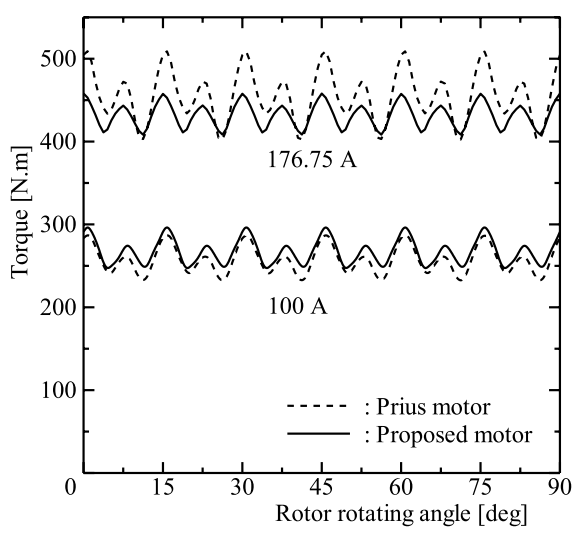

Fig. 14. Comparison of torque with Prius-like motor

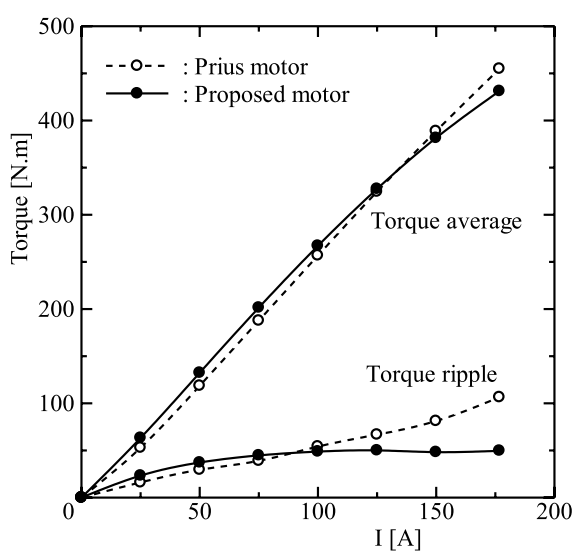

Fig. 15. Characteristic of torque and stator current 


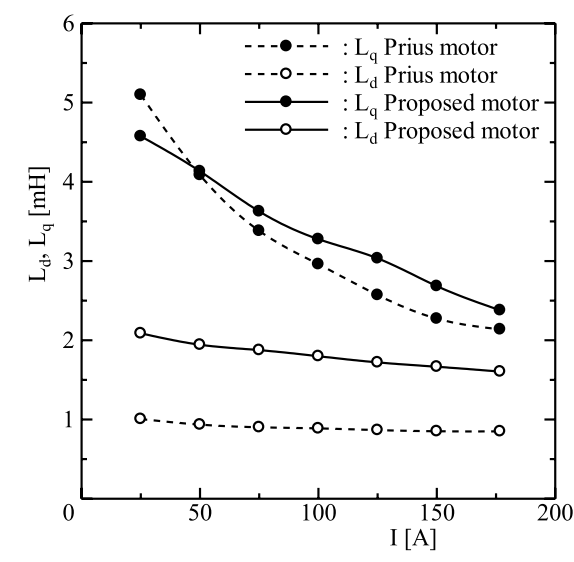

Fig. 16. Characteristics of $L_{d}$ and $L_{q}$

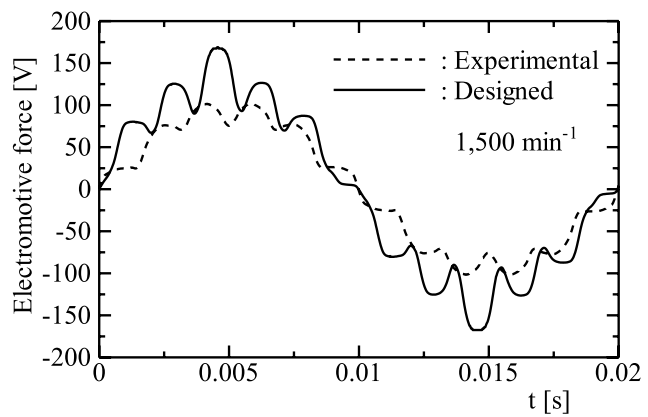

Fig. 17. Measured electromotive force

$q$-axis inductances, $L_{d}$ and $L_{q}$, respectively, of the designed motor and the Prius-like motor. It is found that $L_{d}$ of the designed motor is larger than that of the Prius-like motor. This is caused by the thin PMs in the designed motor. As a result, the reluctance torque, which is proportional to the difference of $L_{q}$ and $L_{d}$, is smaller than that for the Prius-like motor. Because the output torque comprises a PM torque and a reluctance torque, the reduction of reluctance torque causes the reduction of output torque.

3.4 Comparison of Measured Results We have manufactured the designed rotor as shown in Fig. 11(a). Figure 17 shows the measured electromotive force when the rotor is rotating at a speed of $1,500 \mathrm{~min}^{-1}$. The effective value and fundamental component of the electromotive force are $96.3 \mathrm{~V}$ and $133.8 \mathrm{~V}$, respectively, and those for the experimental motor are $68.2 \mathrm{~V}$ and $95.6 \mathrm{~V}$, respectively. Therefore, the electromotive force of the designed motor is 1.4 times larger than that of the experimental motor. Figure 18 shows the inductance measured by an LCR meter at $100 \mathrm{~Hz}$. The obtained $d$ and $q$ inductances are $12.69 \mathrm{mH}$ and $28.37 \mathrm{mH}$, respectively, for the designed motor and $12.51 \mathrm{mH}$ and $29.37 \mathrm{mH}$, respectively, for the experimental motor. The developed torque of IPMSM is expressed by

$$
T=p \Phi I \cos \beta+0.5 p\left(L_{q}-L_{d}\right) I^{2} \sin 2 \beta \ldots \ldots \ldots \ldots
$$

where $p, \Phi, I$, and $\beta$ are pole pairs, flux linkage, stator current, and phase angle of stator current, respectively. Although $\left(L_{q}-L_{d}\right)$ of the designed motor is somewhat small, the flux linkage is 1.4 times greater than that of the experimental motor.

Figure 19 shows the torque-current characteristics when $\beta$ is set to approximately 0 . The developed torque calculated

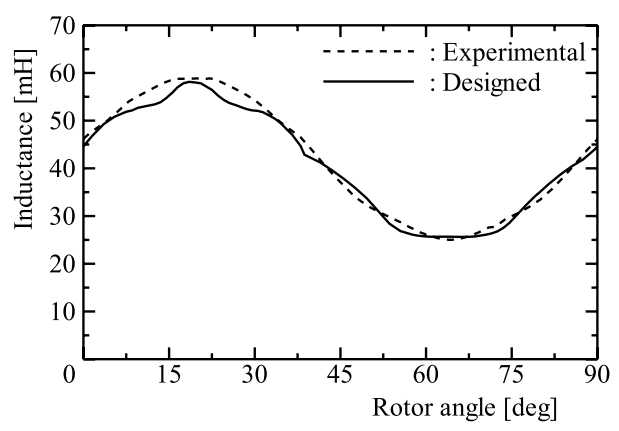

Fig. 18. Measured inductance

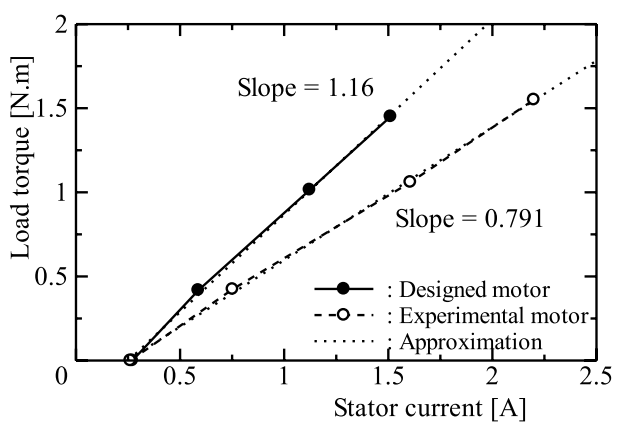

Fig. 19. Measured torque characteristics

by the measured electromotive force is $T=0.75 I$ for the experimental motor and $T=1.05 \mathrm{I}$ for the designed motor. These values are approximately the same as the slope shown in Fig. 19. The differences are generated by the fact that $\beta$ is not controlled to be exactly 0 . Therefore, it is verified that the measured torque of the designed motor is larger than that of the experimental motor under the same stator current.

\section{Conclusions}

In this study, we designed the rotor structure of PM synchronous motors. The proposed optimization process combines the topology optimization method and a method that considers the ease of manufacturing. We assumed four hexahedron PMs similar to the rotor shapes obtained by the proposed method for reasons of manufacturing ease. The obtained rotor of a compressor motor for an air conditioner has $32 \%$ more average torque than that of the experimental motor with the same stator. The motor designed as a second example achieved a larger torque/current than that of the Prius-like motor at a low output power. Experimental results showed that the electromotive force of the designed motor was 1.4 times greater than that of the experimental compressor motor, which resulted in the higher torque.

The authors would like to appreciate the cooperation in the experiment by Mr. Mizuno, Gunma University.

\section{References}

( 1 ) N. Bianchi and S. Bolognani: "Influence of Rotor Geometry of an IPM Motor on Sensorless Control Feasibility", IEEE Trans. Ind. Appl., Vol.43, No.1, pp.87-96 (2007)

( 2 ) N. Imai, S. Morimoto, M. Sanada, and Y. Takeda: "Influence of Rotor Configuration on Sensorless Control for Permanent-Magnet Synchronous Motors", IEEE Trans. Ind. Appl., Vol.44, No.1, pp.93-100 (2009)

( 3 ) W. Shanshan, D.D. Reigosa, Y. Shibukawa, M.A. Leetmaa, R.D. Lorenz, and 
Y. Li: "Interior Permanent-Magnet Synchronous Motor Design for Improving Self-Sensing Performance at Very Low Speed", IEEE Trans. Ind. Appl., Vol.45, No.6, pp.1939-1946 (2009)

( 4 ) K. Yamazaki and H. Ishigami: "Rotor-Shape Optimization of InteriorPermanent-Magnet Motors to Reduce Harmonic Iron Losses", IEEE Trans. Ind. Appl., Vol.57, No.1, pp.61-69 (2010)

( 5 ) M. Barcaro, N. Bianchi, and F. Magnussen: "Rotor Flux-Barrier Geometry Design to Reduce Stator Iron Losses in Synchronous IPM Motors Under FW Operations", IEEE Trans. Ind. Appl., Vol.46, No.5, pp.1950-1958 (2010)

( 6 ) G. Pellegrino, P. Guglielmi, A. Vagati, and F. Villata: "Core Losses and Torque Ripple in IPM Machines: Dedicated Modeling and Design Tradeoff", IEEE Trans. Ind. Appl., Vol.46, No.6, pp.2381-2391 (2010)

( 7 ) Z.Q. Zhu, D. Howe, and Z.P. Xia: "Prediction of open-circuit air gap field distribution in brushless machines having an inset permanent magnet rotor topology", IEEE Trans. on Magn., Vol.30, No.1, pp.98-107 (1994)

( 8 ) D.N. Dyck and D.A. Lowther: "Automated design of magnetic devices by optimizing material distribution", IEEE Trans. on Magn., Vol.32, No.3, pp.1188-1193 (1996)

( 9 ) J.K. Byun, S.Y. Hahn, and I.H. Park: "Topology optimization of electrical devices using mutual energy and sensitivity", IEEE Trans. on Magn., Vol.35, No.5, pp.3718-3720 (1999)

(10) C.H. Im, H.K. Jun, and Y.J. Kim: "Hybrid genetic algorithm for electromagnetic topology optimization", IEEE Trans. on Magn., Vol.39, No.5, pp.2163$2169(2003)$

(11) S. Wang, D. Youn, H. Moon, and J. Kang: "Topology optimization of electromagnetic systems considering magnetization direction", IEEE Trans. on Magn., Vol.41, No.5, pp.1808-1811 (2005)

(12) H. Shim, S. Wang, and K. Hameyer: "Topology optimization of magneto thermal systems considering eddy current as Joule heat", IEEE Trans. on Magn., Vol.43, No.4, pp.1617-1620 (2007)

(13) D.H. Kim, J.K. Sykulski, and D.A. Lowther: "The implications of the use of composite material in electromagnetic device topology and shape optimization”, IEEE Trans. on Magn., Vol.45, No.3, pp.1154-1157 (2009)

(14) J.S. Choi and J. Yoo: "Structural topology optimization of magnetic actuators using Genetic algorithms and ON/OFF sensitivity", IEEE Trans. on Magn., Vol.45, No.5, pp.2276-2279 (2009)

(15) T. Labbe and B. Dehez: "Convexity-oriented mapping method for the topology optimization of electromagnetic devices composed of iron and coils", IEEE Trans. on Magn., Vol.46, No.5, pp.1177-1185 (2010)

(16) J. Lee and N. Kikuchi: "Structural topology optimization of electrical machinery to maximize stiffness with body force distribution", IEEE Trans. on Magn., Vol.46, No.10, pp.3790-3794 (2010)

(17) N. Takahashi, T. Yamada, and D. Miyagi: "Examination of optimal design of IPM motor using ON/OFF method", IEEE Trans. on Magn., Vol.46, No.8, pp.3149-3152 (2010)

(18) S. Park and S. Min: "Design of magnetic actuator with nonlinear ferromagnetic material using level-set based topology optimization", IEEE Trans. on Magn., Vol.46, No.2, pp.618-621 (2010)

(19) K. Watanabe, F. Campelo, Y. Iijima, K. Kawano, T. Matsuo, T. Mifune, and H. Igarashi: "Optimization of inductors using Evolutionary algorithms and its experimental validation", IEEE Trans. on Magn., Vol.46, No.8, pp.3393$3396(2010)$

(20) Y. Okamoto, Y. Tominaga, and S. Sato: "Topological Design for 3-D Optimization Using the Combination of Multistep Genetic Algorithm with Design Space Reduction and Nonconforming Mesh Connection", IEEE Trans. on Magnetics, Vol.48, No.2, pp.515, 518 (2012)

(21) I. Hahn: "Heuristic Structural Optimization of the Permanent Magnets Used in a Surface Mounted Permanent-Magnet Synchronous Machine", IEEE Trans. on Magnetics, Vol.48, No.1, pp.118, 127 (2012)

(22) T. Ishikawa, M. Kaneda, and A. Yamagiwa: "Optimal material distribution design of interior permanent magnet synchronous motor using Genetic algorithm", The 10th biennial IEEE Conf. Electromagnetic Field Computation, pp.2-4 (2002)

(23) T. Ishikawa, K. Yonetake, and N. Kurita: "An optimal material distribution design of brushless DC motor by Genetic algorithm considering a cluster of material", IEEE Trans. on Magn., Vol.47, No.5, pp.1310-1313 (2011)

(24) T. Ishikawa and K. Nakayama: "Topology Optimization of Rotor Structure in Brushless DC Motor with Concentrated Windings Using Genetic Algorithm Combined with Cluster of Material", IEEE Trans. on Magn., Vol.48, No.2, pp.899-902 (2012)

(25) T. Ishikawa, K. Nakayama, and N. Kurita: "Optimization of Rotor Topology in PM Synchronous Motors by Genetic Algorithm Considering Cluster of Materials and Cleaning Procedure", Compumag 2013, PA4-9, Budapest (2013)

Takeo Ishikawa (Senior Member) graduated from Tokyo Institute of

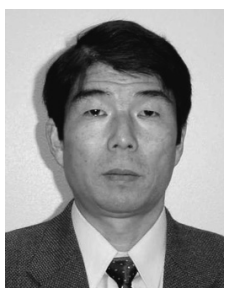
Technology in 1983. He joined Gunma University in 1983, and now he is a professor. His research interests include electrical machine and power electronics. He received the 1998 best paper award of IEEE Transaction on Vehicular Technology. He is a senior member of IEEE.

Peijie Xie (Student Member) received M.E. degree from Gunma Uni-

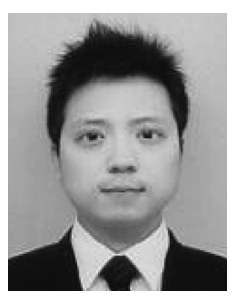
versity in 2014. He joined Nissan Motor Co., Ltd. in 2014. His research interests include electric machine and optimization.

Nobuyuki Kurita (Member) received B.S. degree and M.S. degree

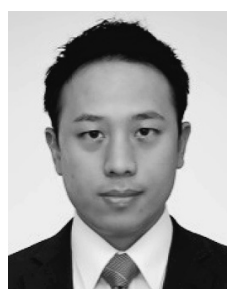
from Ibaraki University in 2001 and 2003, respectively. And he received his Ph.D. degree in engineering from Ibaraki University in 2006. He joined Gunma University as an assistant professor in 2009. His research interests include application of magnetic bearings and self-bearing motor. Dr. Nobuyuki Kurita is a member of IEEE and IEEJ. 